\title{
Multiple Human Bodies: Psychological understanding of Holistic Approach and Intuition
}

\author{
Dr. Amit Gosar
}

\begin{abstract}
The existence of the human system is generally considered by limiting it to the physical body and physical reality for most of the practical purposes. The whole biological science evolved after Isaac Newton's finding of the smallest element having particle nature. But the discovery of Albert Einstein of smallest element having wave nature and his great invention of $\mathrm{E}=\mathrm{MC2}$, has changed the direction and dimension of the physical science. However, ancient Indian literature has said it thousands of years ago and has explained the multidimensionality of the human existence and also about multiple bodies other than this physical body. Different aspects of this multiple dimensionality have been reviewed and are covered in this article. These explanations can throw light of many of the complex psychological and behavioral aspects of the human existence. The phenomenon of intuition has also been explained w.r.t. multiple bodies concept.
\end{abstract}

Index Terms - Human bodies, Chakra, endocrine system, seven principles, seven rays, Maslow's hierarchy, theory of mind, manifestation of diseases.

\section{INTRODUCTION}

Quantitative scientific research generally follows a cause-effect relationship study, especially in medicinal discoveries. Cause and effect is one of the most commonly misunderstood concepts in science in an attempt to add legitimacy to research. This is mainly because to have an arithmetic expression to any scientific research, a linear mathematical expression is required. In case of developing medicines for any disease, the basic assumption made always is that the disease progresses in a linear manner. And there is always a cause which have the effect as a disease. This cause-effect relationship is again considered linear in modern medical scientific discoveries.

Mind, body, soul and spirit in transactional analysis: An integral approach to relationship, Gordon Law (2006) has published a book on role of mind as very important factor in any relationship. This role is much more important than the human body and he also touched upon the importance of soul and spirit. As per Gordon Law, the transactional analysis cannot be fully explained unless you consider the approach of Mind, body, soul and spirit.

Since the evolution and now more after socialization, the biological threats and issues of humankind are shifting more towards the psychological dimensions. The psychological issues are very complex and every person has a unique issue and hence even the therapy to be employed has to be unique

Dr. Amit Gosar, Department of Masters in Business Administration, Sikkim Manipal University, Navi Mumbai, India every time. This has now led to an eclectic approach in the psychotherapy. Eclectic therapy is a therapeutic approach that incorporates a variety of therapeutic principles and philosophies in order to create the ideal treatment program to meet the specific needs of the patient or client. The parallel development in the field of psychology is the holistic approach. Holistic psychotherapy is an approach which helps clients to heal by taking the entire human system and their life experiences into consideration for assessment and treatment purposes. In other words, where traditional methods of psychotherapy consider the psychological complications of problems and behaviors; holistic approach evaluates and treats from physical and spiritual contexts as well as a psychological or mental ones.

\section{SEVEN BODIES OF HUMAN:}

And to understand this, it is very important to understand the multidimensionality or multi body concept of the human system. The human system is a nonlinear system and cannot be understood by applying simple linear arithmetic approaches. Ancient Indian scriptures, including Vedas, have always talked about human system comprising of seven bodies and the physical body being the last layer of the system. These seven bodies are as given below.
1. Physical Body
2. Etheric Body
3. Astral Body
4. Mental Body
5. Spiritual Body
6. Cosmic Body
7. Nirvanic Body

In the first seven years of life, the sthul sharir - the physical body alone is formed. The other bodies are in seed form. They have a potential for growth but they lie dormant in the beginning of life. So the first seven years are years of limitation.

In the next seven years - that is from seven years to fourteen years - the bhawa sharir, the etheric body, develops. These seven years are years of emotional growth of the individual. This is why sexual maturity, which is the most intense form of emotion, is reached at the age of fourteen.

In the third seven-year period, between the ages of fourteen and twenty-one, the sukshma sharir, the astral body, develops. In the second body emotion is developed; in the third body reasoning, thinking and intellect are developed. This is why no court of law holds a child responsible for his actions up to the age of seven, because the child has only the physical body. Also the age of 21 is considered as a milestone age, beyond which, an individual is considered as a mature 
adult who can now independently take the responsibility of self.

The forth body is the psyche - the manas sharir. This body has its own wonderful experiences. At this stage, both Fluid and Crystallized intelligence are at the optimum ratio and the individual and be very productive and taking decisions which will have impact on the rest of the life. All major decisions, like selecting the career, getting married, buying house etc. generally are taken during this period.

The atma sharir - the fifth body, which is called the spiritual body - is of great value. If growth in life continues in the proper manner, then by the age of thirty-five this body should be fully developed. This body is responsible for the self-awareness. The human can change in terms of behaviors, thought pattern etc. till development of this body. Those who can't achieve this development, then can't be change in rest of the life. The development of this body is very rare because even fourth body also develops in very few individuals.

The sixth body is the brahma sharir - the cosmic body. When a person evolves beyond his atman, when he is willing to lose it, he enters the sixth body. If mankind develops scientifically the natural development of the sixth body would take place at the age of forty-two, and that of the nirvana sharir - the seventh body - at the age of forty-nine. The seventh body is the nirvanic body which is no-body - which is a state of bodilessness, an incorporeal state. This is the ultimate state where only the void remains - not even the brahman, the cosmic reality, but only the emptiness. Nothing has remained; everything has disappeared.
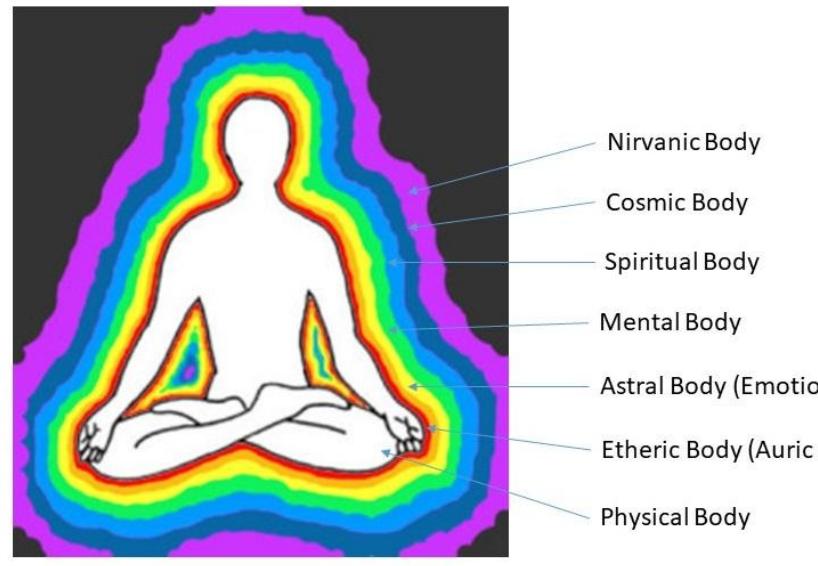

Figure 1 : Diagrammatic representation of seven bodies.

So, for average population first four bodies are predominately developed. The whole psychological and behavioral sciences works with the framework of these four bodies. Book, "The secret", Rhonda Byrne (2006), explains the principle of law of attraction. The law of attraction has a three step process.

Step 1 : Visualization of the thing, one wants to have, as if it already has been received or achieved.

Step 2 : Feeling joy of receiving it while visualizing

Step 3 : It will come in to reality.

Now this process can be explained by taking into account the 4 bodies. The fourth body is a mental body, which is responsible for thoughts. Thoughts are energy and once you think something, you will start feeling that emotion. Hence the thought energy will get converted into emotional energy, which then gets converted into auric energy and then it appears into physical reality. Here the determining factors, about how fast the manifestation of thoughts will take place, are :

1. Intensity of thought

2. Frequency of thought

3. Duration of thought

If the thought of a desire is very intense and that thought comes very frequently and also when it comes, the duration of that thought is very long, then manifestation will happen fast as it will travel fast through thought to emotion to auric to physical reality.

Dreams are also much connected to these bodies they differ in type based on their connection with respective body. Sigmund Freud has given great emphasis on dream analysis for understanding the suppressed desired which are coming from person's id. He has also described that human mind is also having different components viz. conscious, subconscious, unconscious and collective unconscious. The conscious, a term coming from western psychology, is a physical body, the subconscious and unconscious are etheric body and the collective unconscious id astral body. The dream of respective body are different and sometimes misunderstood also. As per Sigmund Freud, the dreams coming because of suppressed desire are coming from unconscious, however these dreams are from physical body only and not from the etheric body. If we suppress our desire of eating and we do fast, there are all the chances that we get dream of tasty food and this is not from unconscious but it's purely from the physical body. Hence understanding these bodies, will help understanding psychoanalytical diagnostics of illnesses.

The collective nonconscious and collective conscious are two important aspects. Certainly, as per Freud, these two are the deeper parts of the human mind. Dreams coming from these two parts provide information which is coming from the collectiveness. Intuition is one such process coming from Mighyer bodies. Once the development of higher bodies starts odbe level of awareness raises. The energy of the human system then raises and becomes one with the universe. At this stage, the individual start gaining information about future, which is termed as "Intuition". "Déjà vu" is also a similar phenomenon, which comes purely from the collective nonconscious, where as intuition comes from both collective nonconscious and collective conscious part of the human system.

Further these seven body can be correlated with seven Chakra system and the emotions attached to each chakra. Again, understanding this in detail can help understanding the basic route cause of any psychological issue and can be then treated holistically.

Travelling from Physical to Nirvanic or causal body, we have seven major chakras connected to them. These chakras are power house and provides energy to associated organs of the physical body. Also these chakras are associated with different emotions and each chakra is connected with one gland each of the endocrine system. 


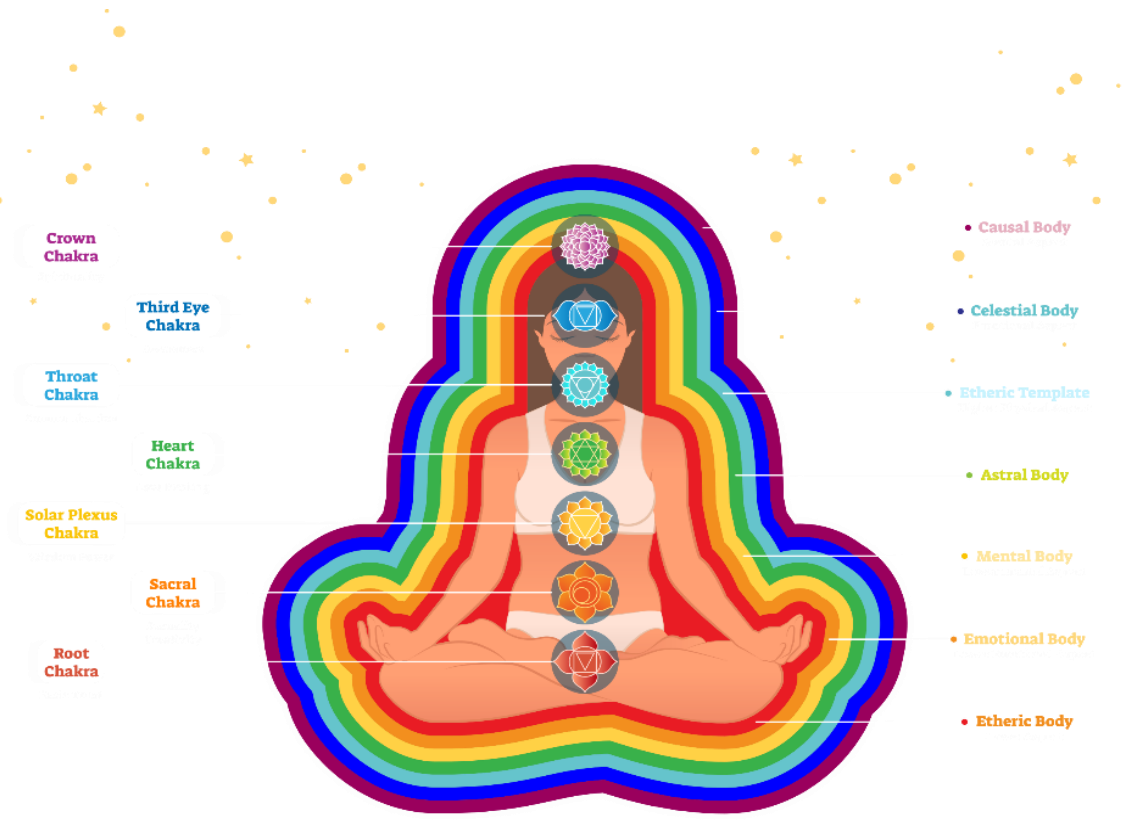

Figure 2 : Energy bodies and chakras

Table 1 : Correlation between seven bodies, seven chakras, associated emotions, associated endocrinal glans and associated hierarchy of needs.

\begin{tabular}{|l|c|l|c|c|}
\hline Energy Bodies & Chakras & Emotions & Glands associated & Maslow's hierarchy of needs \\
\hline Nirvanic Body & Crown & $\begin{array}{c}\text { Awareness, Empowered, } \\
\text { Calm }\end{array}$ & Penial & \multirow{2}{*}{ Self Actualization } \\
\hline Cosmic Body & Third Eye & Clear, empathetic, focused & Pituitary & \\
\hline Spiritual Body & Throat & $\begin{array}{l}\text { Truthfulness, honesty, } \\
\text { power }\end{array}$ & Thyroid \\
Mental Body & Heart & $\begin{array}{l}\text { Love, Gratitude, } \\
\text { Compassion }\end{array}$ & Thymus & \multirow{2}{*}{ Self-esteem } \\
\hline Astral Body & Solar Plexus & Self-esteem, Confidence, Hope & Pancreas & Love and Belongingness \\
\hline Etheric Body & Sacral & Passion, Creativity, & Adrenaline Gland & Safety \\
\hline Physical Body & Root & Security, sex & Reproductive Glands & Physiological \\
\hline
\end{tabular}

and best way of all in which to think of man is to regard him

In the above table, the association between seven bodies, seven chakras, seven endocrinal glands, different emotions and Needs as per Maslow's hierarchy have been shown. Any psychological issue, associated with respective chakra and thus with respective endocrinal gland will cause hormonal imbalance in the human body and accordingly respective negative emotions will take it over, leading to anxiety and depression or any other psychosomatic illnesses. Hence the Holistic approach in treating such illnesses is very effective, as it will not only cure the symptom, but all will take care of the manifestation process of that illness.

Theosophists have tried understanding the wider knowledge and spiritual growth of a human being. Annie Besant, in her book "Seven principles of man" (1909), presented in Theosophical Manual No. 1, has described seven principles, which are also signifying about human having multiple bodies. "Man according to the Theosophical teaching is a sevenfold being, or, in the usual phrase, has a centenary constitution. Putting it in another way, man's nature has seven aspects, may be studied from seven different points of view, is composed of seven principles. The clearest as one, the Spirit or True Self; this belongs to the highest region of the universe, and is universal, the same for all; it is a ray of God, a spark from the divine fire. This is to become an individual, reflecting the divine perfection, a son that grows into the likeness of his father. For this purpose the Spirit, or true Self, is clothed in garment after garment, each garment belonging to a definite region of the universe, and enabling the Self to come into contact with that region, gain knowledge of it, and work in it. It thus gains experience, and all its latent potentialities are gradually drawn out into active powers These garments, or sheaths, are distinguishable from each other both theoretically and practically. If a man be looked at clairvoyantly each is distinguishable by the eye, and they are separable each from each either during physical life or at death, according to the nature of any particular sheath. Whatever words may be used, the fact remains the same - that he is essentially sevenfold, an evolving being, part of whose nature has already been manifested, part remaining latent at present, so far as the vast majority of humankind is concerned. Man's consciousness is able to function through as many of these aspects as have been already evolved in him into activity." 
Table 2 : Classification of human bodies according to the seven Principles by Annie Besant

\begin{tabular}{|r|l|l|}
\hline 7 & Atmâ & \multirow{2}{*}{ Spiritual } \\
\hline \hline 6 & Buddhi & Mental \\
\hline \hline 5 & Manas & Astral \\
\hline \hline 4 & Kâma & \multirow{2}{*}{ Physical } \\
\hline \hline 3 & Prâna & \\
\hline \hline 2 & Etheric Double & \\
\hline \hline 1 & Dense Physical Body \\
\hline
\end{tabular}

Theosophically, the man has been studies through his path of evolution as to his lower nature or lower physical dimension. Theosophy teaches that through past ages man was thus slowly built up, stage by stage, principle by principle, until he stood as a quaternary. Annie Besant has thus given an understanding about this quaternary system of human being.

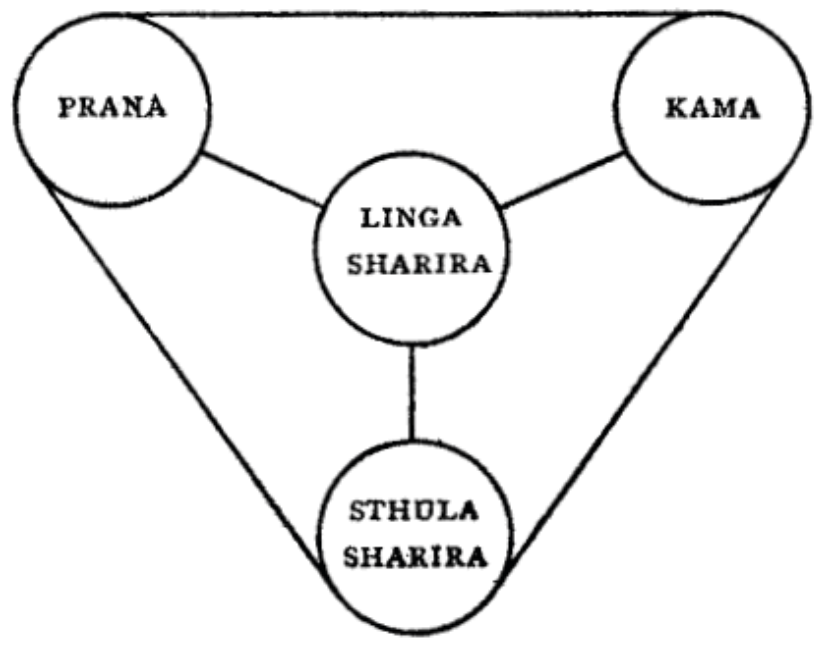

Figure 3 : Diagram of the Quaternary; transitory and mortal; see Secret Doctrine, Volume I, page 262

In the everlasting evolution of human, the progression was very slow and still hurried through in the personal evolution of each human being. Each principle, which was in the course of ages successively evolved in man on earth, appearing as part of the constitution of each man at the point of evolution reached at any given time, the remaining principles being latent, awaiting their gradual manifestation.

By the means of Quaternary, the explanation about inter connectivity of first 4 human bodies has been provided. This further provides sufficient evidences for understanding the "Law of attraction" as well as manifestation of diseases as a psychosomatic process.

In his book, “The Seven Rays", Earnest Wood (1925), has elaborated the human emotions w.r.t. seven principles of man suggested by Annie Besant. In the common life of men, the rays are exhibited in the following general types:

1. The man of will, seeking freedom through mastery of self and environment: the ruler.

2. The man of love, seeking unity through sympathy: the philanthropist.

3. The man of thought, seeking comprehension through the study of life: the philosopher.
4. The man of imagination, seeking harmony in a three-fold way: the magician, actor and symbolical artist or poet.

5. The man of thought, seeking truth in the world: the scientist.

6. The man of love, seeking God as goodness in the world: the devotee.

7. The man of will, seeking the beauty that is God in the world: the artist and craftsman.

This indicates the quality of thoughts, cognition, emotions and awareness of human living at different Chakras. The person living in lower chakras is more into physical need of acquisition of materialistic goals and power. The person living in higher chakras will be more compassionate and spiritual. And the intuition power grows as the person grows from lower chakras to the higher chakras. This also provides complete understanding about the Maslow's model.

\section{CONCLUSION:}

The human system of mind, body, emotions and consciousness is a dynamic nonlinear system. This system comprises of multiple energy sheaths or multiple bodies. This system is a multidimensional and multidirectional system and cannot be simulated by considering simple and linear algorithmic systems. The human mind also is a complex dynamic system, having conscious, preconscious, subconscious, unconscious and collective unconscious parts. The psychological aspects of conscious and subconscious mind play a very critical role in the behavior of human and human body. The quantum physics also explains it in an effective way as the human body being an expression of the mind. This was explained in theosophical way by Annie Besant by proving the Quaternary structure of Human system. Thus the perceived reality in the object world is a product of quantum consciousness. The disease is a state of non-congruency between the Real, Ideal and Perceived selves. This non congruence occurs through the belief and thought system, which are part of mental body. The speed of manifestation depends on the Intensity, frequency and duration of the thoughts. The complete homeostasis occurs only when these selves are in congruence with each other, in other words all the seven bodies are in sync with each other and the energy flows flawlessly through the chakra system. This can be achieved by adopting the eclectic or holistic approach. For the well-being of the human kind, the holistic approach revolves around the psychological and scientific implementation of the acts or processes that make the ascent of human system.

\section{REFERENCES}

[1] Annie Besant (1909), "The Seven Principles of Man”, Theosophical Manual No.1.

[2] Earnest Wood (1925), "The Seven Rays", The Theosophical Publishing House.

[3] Amit Gosar*; "Direction of life". GJRA, 7(11): 416 - 418, 2018.

[4] Hans J. (Jochen) Scholl; Introduction to Modeling Nonlinear Natural and Human Systems Minitrack; Proceedings of the 35th Hawaii International Conference on System Sciences - 2002.

[5] L. Brizhik and A. Foletti; nonlinear quantum phenomena and biophysical aspects of Complexity related to health and disease; journal of biological regulators \& homeostatic agents, 28 (3), 367 - 376, 2014.

[6] Freud, S. (1915). The unconscious. SE, 14: 159-204.

[7] Freud, S. (1920). Beyond the pleasure principle. SE, 18: 1-64. 
[8] Freud, S. (1923). The ego and the id. SE, 19: 1-66.

[9] Freud, S. (1961). The resistances to psycho-analysis. In The Standard Edition of the Complete Psychological Works of Sigmund Freud, Volume XIX (1923-1925): The Ego and the Id and other works (pp. 211-224).

[10] Amit Gosar*; "Psychoanalytical approach to understand the metaphysics behind the anatomy of lungs and use of Hypnotherapy and Affirmations in the treatment of Asthma: A case study". PIJPS, 3 (2): $20-26,2019$.

[11] Amit Gosar*; "Nonlinearity of Diseases: Psychological Aspects". World Journal of Research and Review (WJRR), 8 (4): 26 - 28, 2019.

[12] Amit Gosar*; "Low self-esteem: A cause for migraine: A psychological cases based Evaluation". GJRA, 8 (5): 1 - 3, 2019. DOI $10.15373 / 22778160$.

[13] Maslow, A.H. (1943). "A theory of human motivation". Psychological Review. 50 (4):

370-96. CiteSeerX 10.1.1.334.7586. DOI: $\underline{10.1037 / \mathrm{h} 0054346}$ - via psychclassics.yorku.ca.

[14] Sapta Chakra, The British Library, MS 24099

[15] ऋग्वेद: सक्तं १.१६४, verse ॥१९॥, Rigveda, Wikisource.

[16] Osho, "The Psychology of the Esoteric", Talks given from 1972.

[17] Marieb, Elaine (2014). Anatomy \& physiology. Glenview, IL: Pearson Education, Inc. ISBN 978-0321861580.

[18] Neave N (2008). Hormones and behavior: a psychological approach. Cambridge: Cambridge Univ. Press. ISBN 978-0521692014. Lay $\underline{\text { summary }}$ - Project Muse. 